\title{
Ground-Penetrating Radar Prospecting in the Peinan Archaeological Site, Taiwan
}

\author{
Lun-Tao Tong ${ }^{1, *}$, Kun-Hsiu Lee ${ }^{2}$, Chang-Keng Yeh ${ }^{2,3}$, Yen-Tsung Huang ${ }^{1}$, and Chih-Yu Liu ${ }^{1}$ \\ ${ }^{1}$ Energy and Environment Research Laboratories, Industrial Technology Research Institute, Hsinchu, Taiwan, ROC \\ ${ }^{2}$ National Museum of Prehistory, Taitung, Taiwan, ROC \\ ${ }^{3}$ Department of Anthropology, National Taiwan University, Taipei, Taiwan, ROC
}

Received 25 May 2012, accepted 14 January 2013

\begin{abstract}
The Peinan archaeological site is the largest prehistoric village in Taiwan. Only small-scale pits are allowed for research purposes because the Peinan site is protected by the Cultural Heritage Preservation Act. Careful selection of the pit locations is crucial for future archaeological research at this site. In this study, a ground-penetrating radar (GPR) survey was applied near the stone pillar to understand the GPR signatures of the subsurface remains. Seven GPR signatures were categorized based on the radar characters shown on the GPR image. A detailed GPR survey with dense parallel survey lines was subsequently conducted in the area of northern extent of the onsite exhibition to map the subsurface ancient buildings. The results were verified by two test pits, which indicate that the distribution of the subsurface building structures can be well recognized from GPR depth slices. It will be very helpful for setting proper pits priorities for future archaeological research, and for making proper design of the new onsite exhibition.
\end{abstract}

Key words: Peinan archaeological site, Prehistoric village, Archaeological geophysics, Ground-penetrating radar, GPR signature, GPR depth slice

Citation: Tong, L. T., K. H. Lee, C. K. Yeh, Y. T. Huang, and C. Y. Liu, 2013: Ground-penetrating radar prospecting in the Peinan archaeological site, Taiwan. Terr. Atmos. Ocean. Sci., 24, 311-321, doi: 10.3319/TAO.2013.01.14.01(T)

\section{INTRODUCTION}

The Peinan archaeological site is the largest and the most intact Neolithic village with a slate coffin burial complex in Taiwan. As proven by Carbon-14 dating, the time of the Peinan site was approximately 2300 to 5300 years old (Lien 1991; NMP 2012). As shown in Fig. 1, it is located on the southeastern foothills of Mt. Peinan and the rightside river terrace of the Peinan River, in SE Taiwan, about $5 \mathrm{~km}$ NW of downtown Taitung. Two photographs taken by Ryuzo Torii in 1896 show big stone pillars standing on the surface which are the earliest records of the Peinan site (Sung 1992; NMP 2012). Based on an oral description of a villager from Peinan, numerous stone pillars were erected on the surface in the 1950s. Today, only the crescent-shaped stone pillar remains at the surface and have become a famous landmark for the Peinan site.

From 1980 to 1988, a 13-stage archaeological excavation was conducted by a team of archaeologists from

\footnotetext{
* Corresponding author

E-mail: tong@itri.org.tw
}

the National Taiwan University to salvage the subsurface remains from the construction of the Peinan train station near the eastern Peinan site. More than 1500 slate coffins and over 20000 stone and pottery artifacts were excavated (Sung and Lien 2004; Lien and Sung 2006). Based on the observation from previous archaeological excavation (Sung and Lien 1987, 2004; Lien 1991, 2008; Lien and Sung 2006; Lee 2009), the main body of a residential house at the site resembled a flat rectangle $11.5 \mathrm{~m}$ in length on the east and west sides and $5.5 \mathrm{~m}$ on the north and south sides. The footing of walls was made of slate boulders and wood. The residential houses of the Peinan tribes were positioned axially in the NS direction and faced Mt. Tulan. Every residential house faced east, looking directly at the rivers and the ocean. In front of the house was a square yard tiled with slates. In the back was an oval shaped stone circle where food and large pottery jugs were stored.

Among the unearthed artifacts, the public was interested in particular the large number of exquisite jade objects. Given the significance of the Peinan site, an outdoor museum and the first prehistoric site park in Taiwan, the 


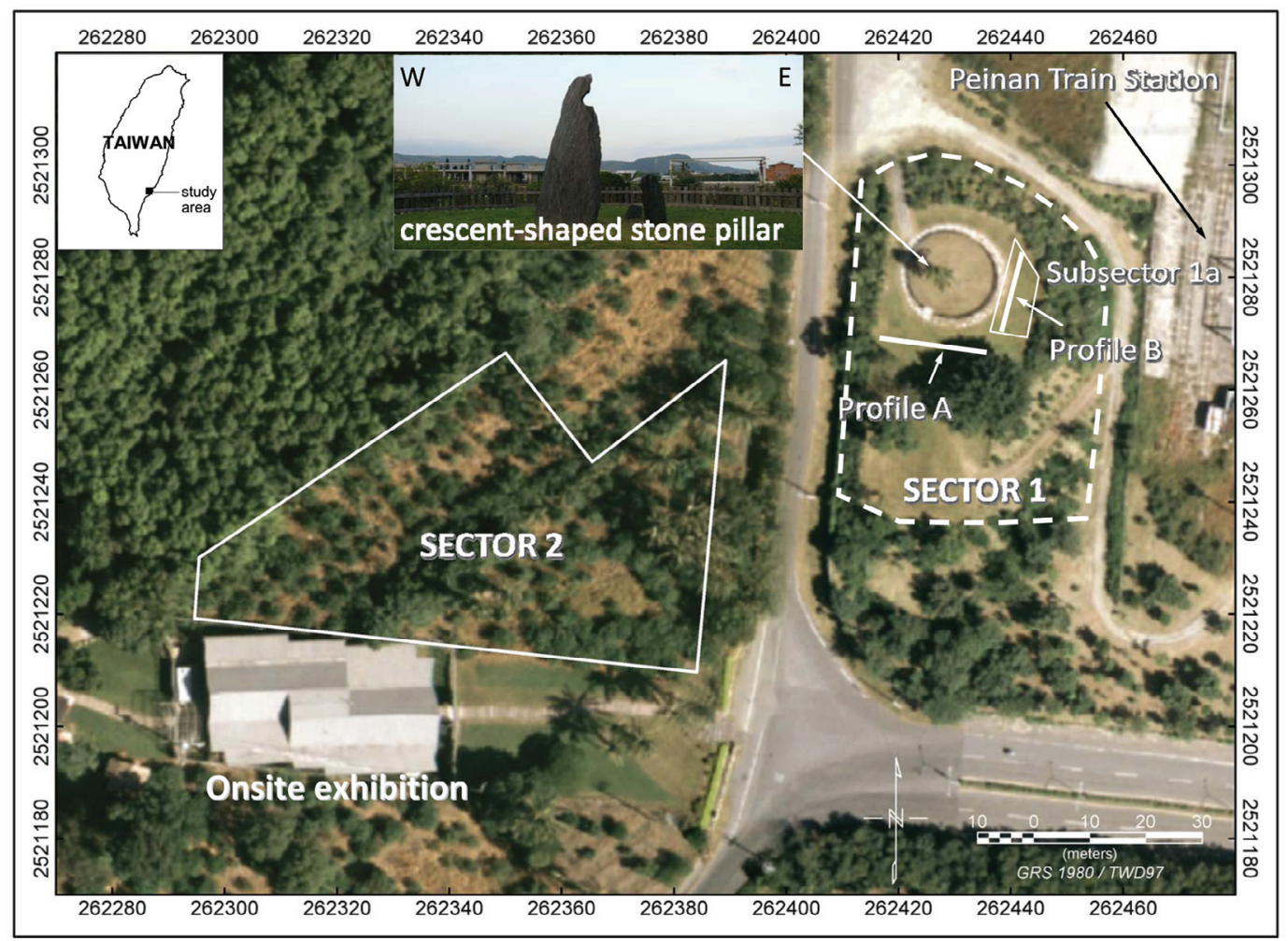

Fig. 1. Location of the Peinan archaeological site and the prospected area, sector 1 and sector 2. The aerial photograph is used as the base map.

Peinan Cultural Park, was built and opened to the public in 1997. During promotion of the Peinan Cultural Park, the first GPR survey (Hsiao and Tong 1995; Tong 1995) was conducted in 1995 at the onsite exhibition (Fig. 1). No more geophysical prospecting had been applied in the Peinan site until 2009.

Careful selection of excavation priorities is essential for future archaeological research at the Peinan site, because complete archaeological excavation of the Peinan site is impractical and impossible due to this site is protected by the Cultural Heritage Preservation Act. The National Museum of Prehistory (NMP) began an archaeo-geophysical study in the Peinan site starting from 2009. A variety of geophysical methods had been tested along three selected profiles. The electromagnetic and magnetic surveys were conducted over the entire Peinan Cultural Park. The ground conductivity map obtained from the electromagnetic survey was successful in mapping the majority of the ancient villages because the basements of the buildings are highly resistive in comparison to the background sediment (Tong et al. 2013). To understand the GPR signatures of the subsurface remains at the Peinan site, we conducted GPR measurements in sector 1 near the stone pillar (Fig. 1). A detailed GPR survey was subsequently performed in sector 2 as shown in Fig. 1 to help in efficient excavation of the subsurface remains in the northern extent of the onsite exhibition in a short fieldwork.

\section{GPR DATA ACQUISITON AND PRE-PROCESSING}

Although geophysical methods have been applied in archaeology over the last several decades, their implementation in Taiwan has been relatively few starting in the middle of the 1990s (e.g., Chen et al. 1995; Hsiao and Tong 1995; Tong 1995; Tong and Chen 1996; Ho et al. 1997; Jeng et al. 2003; Tong et al. 2013). Most of the available documents are in Chinese. Among the geophysical methods, the GPR method has been increasingly and successfully applied in archaeological prospecting (Whiting et al. 2001; Quarto et al. 2007; Shaaban et al. 2009) because of its ability to explore the subsurface at a high resolution (Tong 1993; Bonomo et al. 2009; Chen and Jeng 2011; Tong et al. 2013). A highfrequency electromagnetic pulse was emitted periodically from a transmitting antenna located on the ground surface into the subsurface, and the signal reflected from the interface of the materials with various dielectric constants was recorded by a receiving antenna. Therefore, a high-resolution image can be reconstructed after proper data processing. The current GPR technique involving multi-channels, 3D data processing and visualization can provide a detailed image of subsurface archaeological targets (Francese et al. 2009; Porsani et al. 2010).

The GSSI SIR-10 with a $500 \mathrm{MHz}$ radar antenna was used to perform the GPR survey in this study in 2010. Based on the dielectric constant of the surrounding sediment ob- 
tained previously (Tong et al. 2013), the record length of the radar trace is set to be $60 \mathrm{~ns}$ wherein the penetrating depth is about $3 \mathrm{~m}$. The continuous mode was used to record the radar signal at a transmitting rate of $49.6 \mathrm{KHz}$. More than 100 traces can be obtained in one meter. The interval between traces depends on the speed of the antenna moving along the survey line. Thus, we use RADAN software developed by the GSSI to normalize the trace interval of all GPR image acquired in this study to $2 \mathrm{~cm}$ before further data processing.

\section{ESTIMATION OF GROUND VELOCITY}

The radar velocity of the ground is the crucial parameter for migration and conversion of the 2-way travel time of radar reflection into depth. The common-middle-point (CMP) method is widely used for determining the velocity function of the ground (Travassos and Menezes 2004; Leucci and Negri 2006). However, it may not be suitable for estimating the radar velocity at the Peinan site because no obvious layered stratum within the penetrating depth is present.

Two simple methods were used in this study to estimate the radar velocity of the ground. First, the velocity of the shallow subsurface was calculated using $\mathrm{V}=\mathrm{D} / \mathrm{T}$, where $\mathrm{V}$ is the radar velocity of the ground, $\mathrm{D}$ is the depth of a known object buried at a shallow depth, and $\mathrm{T}$ is the oneway travel time of the radar signal emitted by a $500 \mathrm{MHz}$ radar antenna from the ground surface to the top of the buried object. A steel rod was inserted horizontally into the ground at a depth of $20 \mathrm{~cm}$ to perform the calculation of radar velocity of the shallow subsurface. This method is simple and quick; however, only the radar velocity of the shallow subsurface can be estimated.
The second method used in this study is to estimate the radar velocity of the ground at a specific depth by testing various velocities and comparing the corresponding theoretical diffraction with the diffraction pattern shown on the GPR image to determine the optimally matched velocity at that depth. The curvature of the diffraction from a reflector buried at a specific depth is inversely proportional to the velocity. Thus, it is easy to estimate the radar velocity using the trial-and-error method if a number of diffraction patterns can be observed on the GPR image at various depths. Figure 2a shows the typical GPR image acquired at the Peinan site. A large number of diffractions can be observed on the GPR image; therefore, it is suitable for estimating the velocity at various depths using the trial-and-error method. Figure $2 b$ shows the velocity model determined by matching the diffraction at various depths. As shown in Fig. 2b, the radar velocity of the topsoil is approximately $0.15 \mathrm{~m} \mathrm{~ns}^{-1}$ and decreases with increasing depth. The radar velocity at a depth of $2 \mathrm{~m}$ is approximately $0.05 \mathrm{~m} \mathrm{~ns}^{-1}$. The decrease in velocity with respect to depth may be caused by increasing water content in the soil.

\section{PROSPECTING OF SECTOR 1}

The crescent-shaped stone pillar is the only remaining stone pillar on the surface at the Peinan site. As shown in Fig. 1, the area encircled by white dashed line and labeled as sector 1 retained its natural topography even during the period of salvage excavation from 1980 to 1988. It is believed that the subsurface surrounding the stone pillar and within sector 1 will be rich in prehistoric remains. Two profiles (Fig. 1) near the stone pillar were conducted to study the GPR signatures of the subsurface remains. (a)

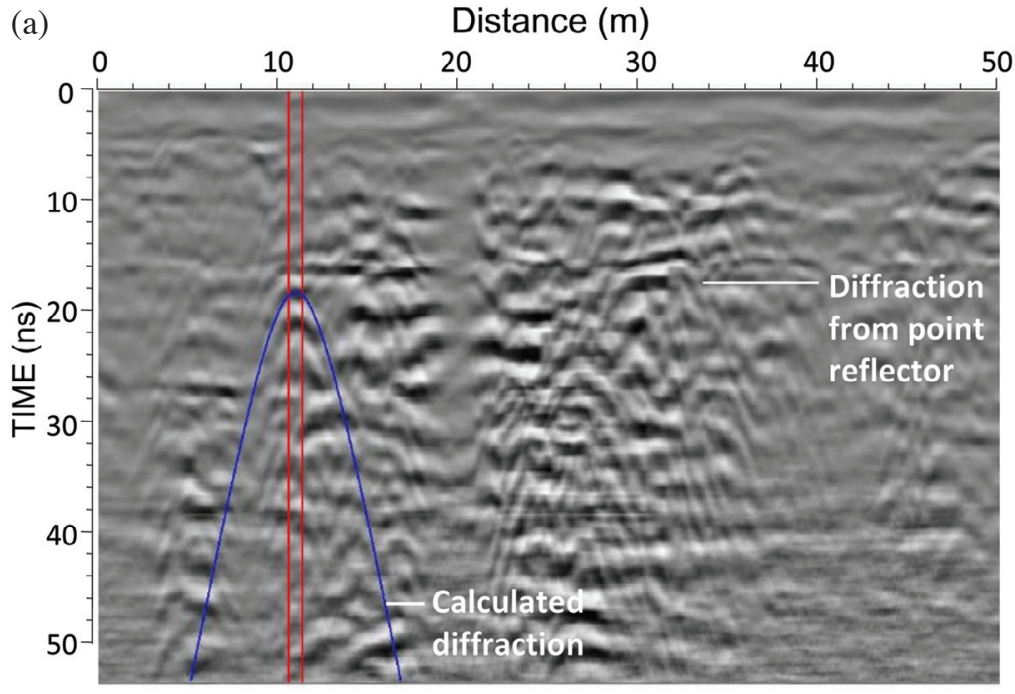

(b)

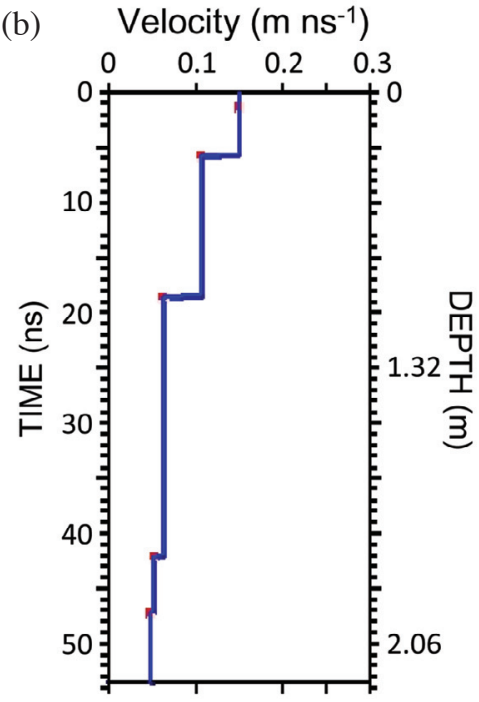

Fig. 2. The typical GPR image acquired in the Peinan site and its velocity model. (a) The gray-scale GPR image after horizontal and vertical filtering. (b) The velocity model obtained from matching the diffraction at various depths. 
The purpose of the data processing is to improve understanding the real location/properties of the anomalies, especially when the data was contaminated by strong noise. For this study, we do not apply complex data processing on the dataset because the anomalies shown on the raw data are already very obvious. We use the RADAN software to process the radar images acquired in this survey area. First of all, the horizontal background noise was reduced by applying a horizontal high pass filtering with a cutoff wavelength of 255 scans. Second, a vertical band-pass filtering with lower and higher cutoff frequency of 250 and $1000 \mathrm{MHz}$ was applied to each trace to improve the $\mathrm{S} / \mathrm{N}$ ratio. Third, an automatic range gain was applied to compensate for amplitude reduction. Finally, the Kirchhoff migration was applied with the velocity function described in Fig. $2 b$.

Figures 3a shows the original GPR images of Profile A. It is difficult to interpret the original radar image in detail because the entire image is contaminated by strong horizontal noise. Figure $3 \mathrm{~b}$ shows the GPR image of profile A in gray mode after horizontal/vertical filtering and automatic range gain. Obvious horizontal background noises were significantly reduced in Fig. 3b when compared with Fig. 3a. The GPR image in gray mode is useful to identify the diffraction pattern which may not be easy to recognize in color mode. Figures $3 \mathrm{c}$ and $\mathrm{d}$ show the migrated radar image in color mode and wiggle model. The GPR image in wiggle mode is useful to recognize the continuous reflections and to figure out those portions with strong radar signals.

Traditional interpretation of radar image is based on the continuation and strength of the reflections shown on the migrated GPR image. In our study, the radar character shown on the radar image is identified by referring its reflection types, relative strength of radar signal, relative frequency and texture. The zone with the same radar characters is classified into the same signature. Seven GPR signatures were categorized in this study by analyzing the radar characters shown on the GPR image produced in different processing steps and display modes (e.g., Figs. 3a - d). For easy comparison, the GPR signatures are labeled and encircled/ denoted by white lines on Fig. 3, descriptions are as below:

\section{(1) Ts: the topsoil}

The top portion of the GPR image consists of weak and flat radar character implied that it is composed of uniform material, and may relate to the topsoil with a thickness of $20-80 \mathrm{~cm}$.

\section{(2) P: the platform structure}

The P-type zone consists of obvious and disordered diffractions, which are much easier to recognize from the gray-scale radar image (Fig. 3b). This indicates that the diffractions are reflected from a gather of boulders buried in the subsurface. Figure 4 shows the photograph taken at the onsite exhibition. Comparison of Fig. 4 with the archaeological features (Fig. 5) observed from the onsite exhibition shows that the platform structure were constructed with slate or schist slabs or boulders, and were normally buried 0.5 to $1.0 \mathrm{~m}$ below ground (Sung 1992). It implies that the zone $P$ with gathered diffractions shown on the GPR image may be associated with the platform structure.

\section{(3) H: the house structure}

As shown in Fig. 3, the H-type zone is frequently distributed between adjacent P-type zones. The response from the radar signal has the characteristics of weak amplitude and scattered diffractions. A number of flat reflections were observed at the bottom of the H-type zone, which may relate to the reflection from the flat slate which acts as the floor of the ancient house (Fig. 4). Referring to Figs. 4 and 5, it implies that the H-type zone may be associated with the indoor or street areas and was subsequently filled with sediments.

\section{(4) Ps: the paleosurface}

As shown in Figs. 3c and d, a weak and slight sloping reflection, labeled Ps, appears at a depth of $2.3-2.5 \mathrm{~m}$ was interpreted as the paleosurface. A large number of considerable reflections and diffractions (P-zone and H-zone) were observed above Ps, whereas a few obvious reflections $(\mathrm{Cr})$ were observed below Ps. The layer between Ps and the bottom of Ts may be linked to the Peinan culture layer (Sung and Lien 2004; Lee 2009), which consists of rich ancient remains.

\section{(5) Cr: the coffin reflection}

A number of strong reflections with limited width, labeled $\mathrm{Cr}$, were observed on the migrated radar image (Fig. 3c), which may be related to slate coffin buried below Ps. This observation consists of the finding from previous excavation (Sung and Lien 2004; Lee 2009) where most of the slate coffins were buried below paleosurface.

\section{(6) Ds: the deep stratum}

The lower portion below the Ps mainly consists of weak and sub-horizontal radar signal. It indicates that Ds can associate with the undisturbed sedimentary basement in the Peinan archaeological site.

\section{(7) Fr: the flat reflection}

As shown in Fig. 6, a strong, continuous, and slightly dipping reflection was observed, labeled Fr, which may be associated with a large slate pillar because its width may exceed $2 \mathrm{~m}$. To understand the detailed spatial distribution of Fr, a set of parallel GPR profiles were performed with a spacing of $0.5 \mathrm{~m}$ in the subsector $1 \mathrm{a}$ (Fig. 1). Figure 7 shows the block view of the radar image with the upper depth slice cut at $1.1 \mathrm{~m}$. The width and length of Fr were estimated at 2 and $4 \mathrm{~m}$, respectively. This particular reflection anomaly may relate to a toppled stone pillar or a flat slate buried in the subsurface. 

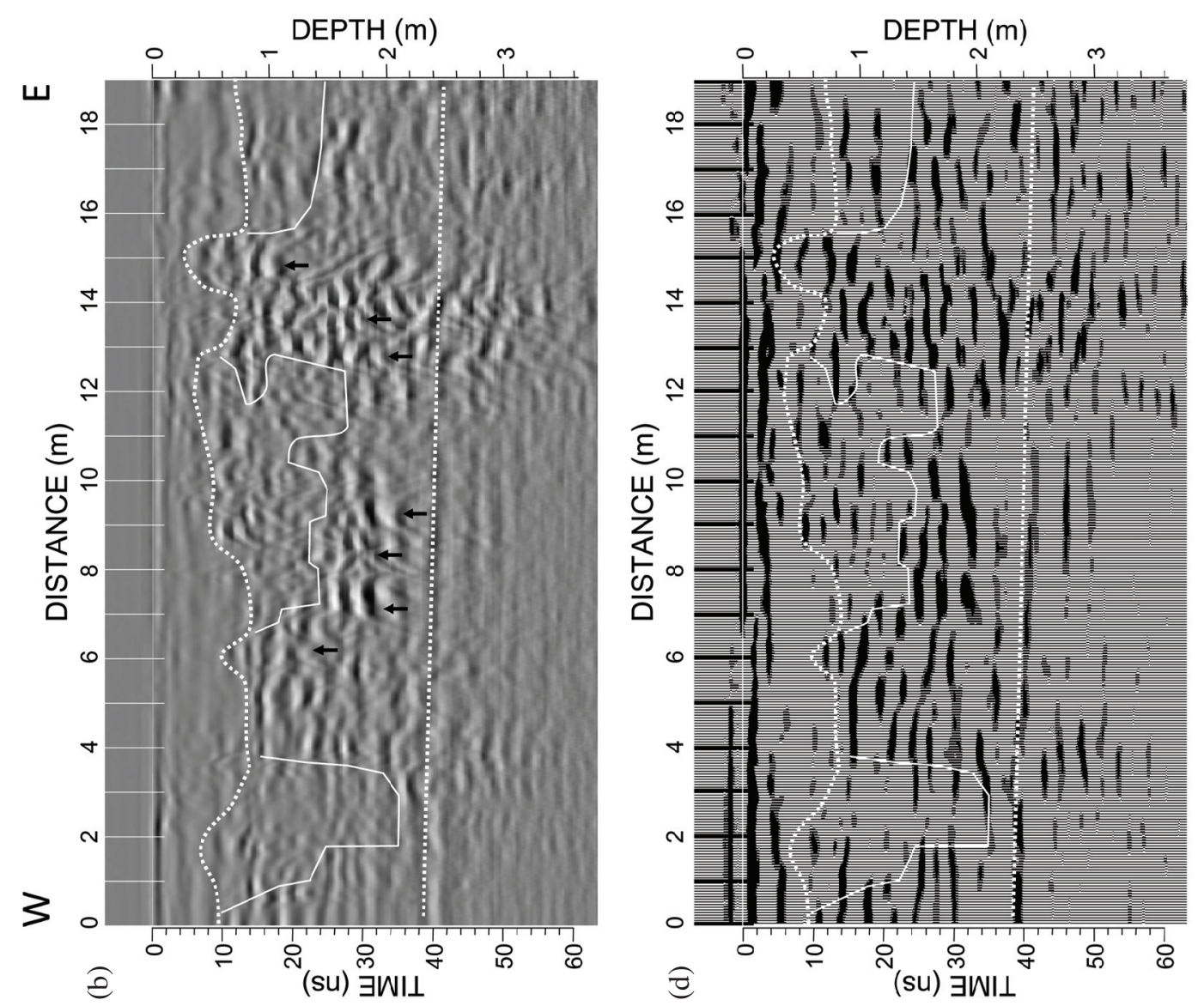

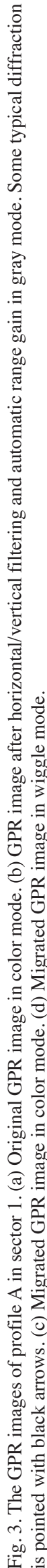
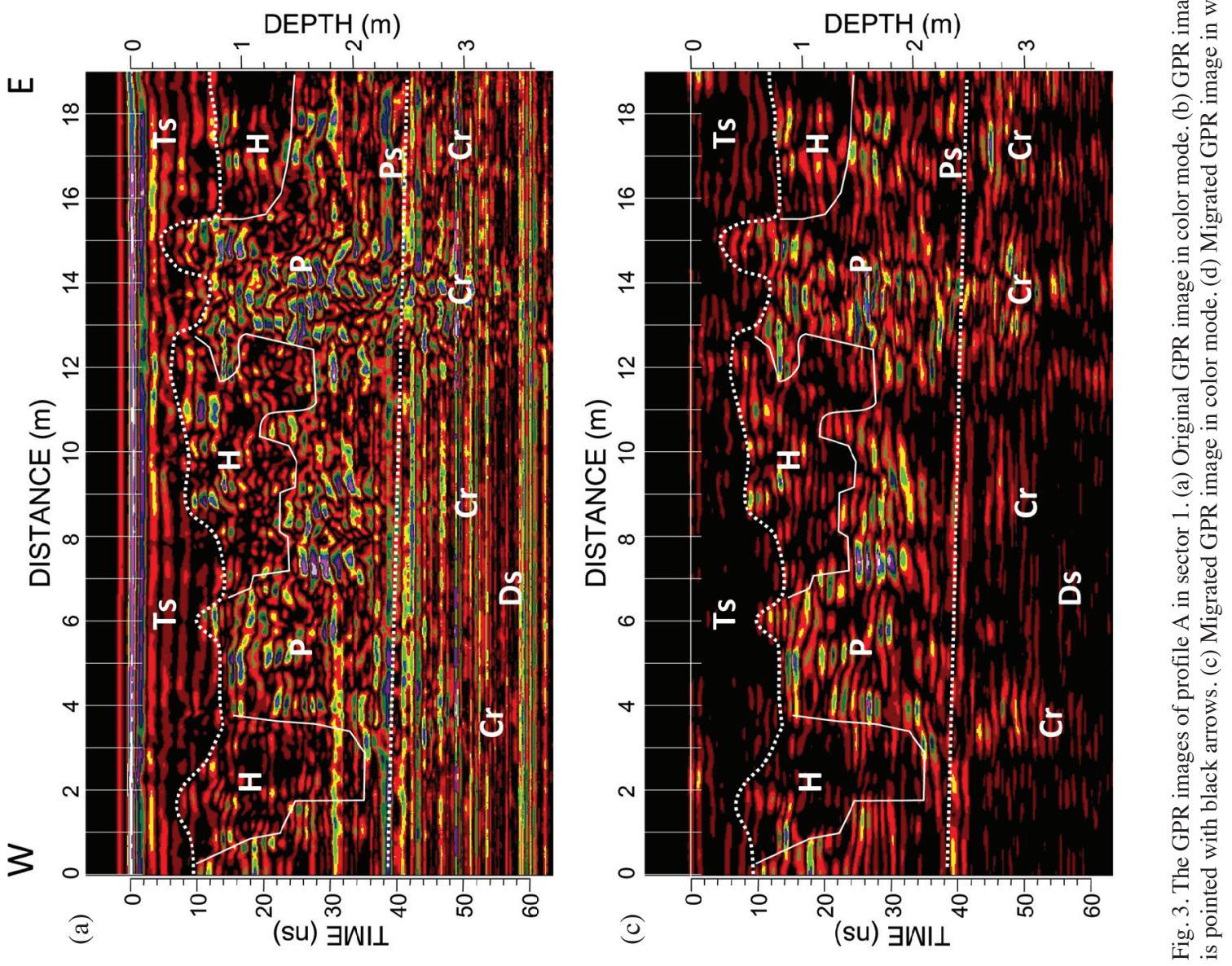


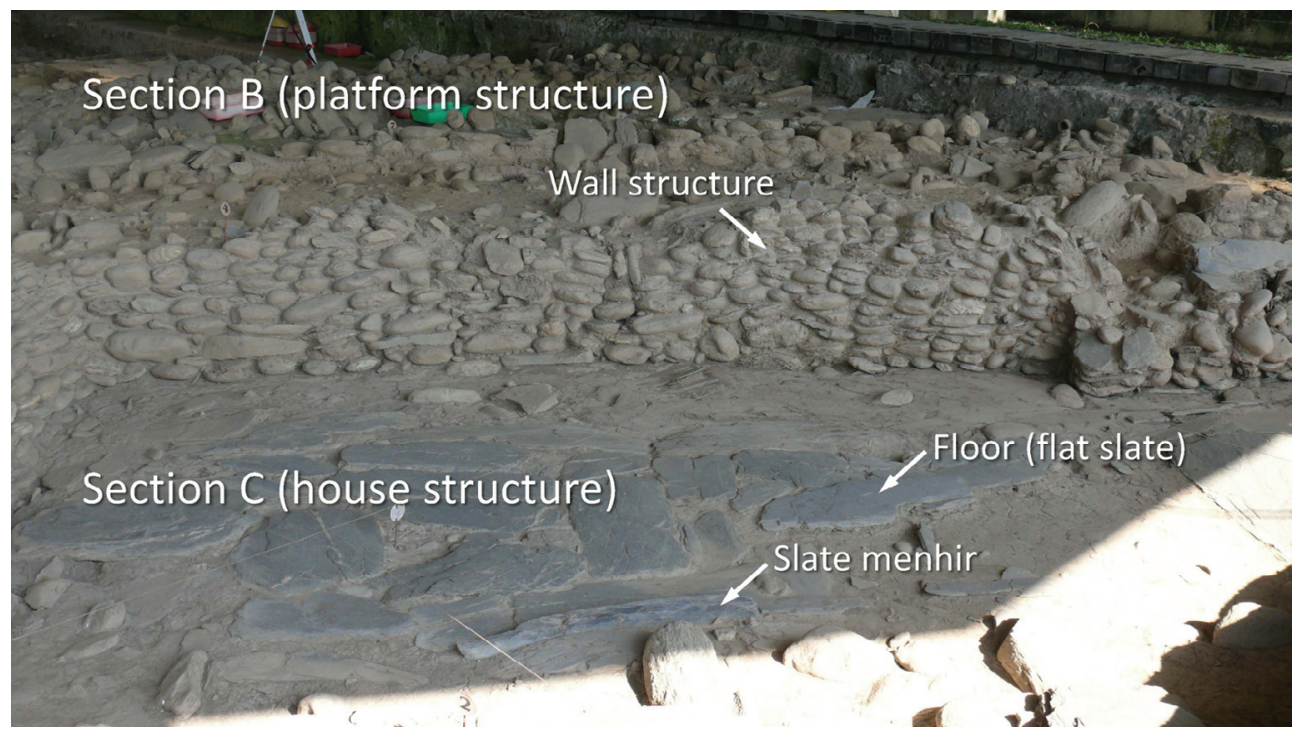

Fig. 4. Photograph taken at the onsite exhibition. The platform structure was constructed with boulders, and the floor of the house was made of flat slates.

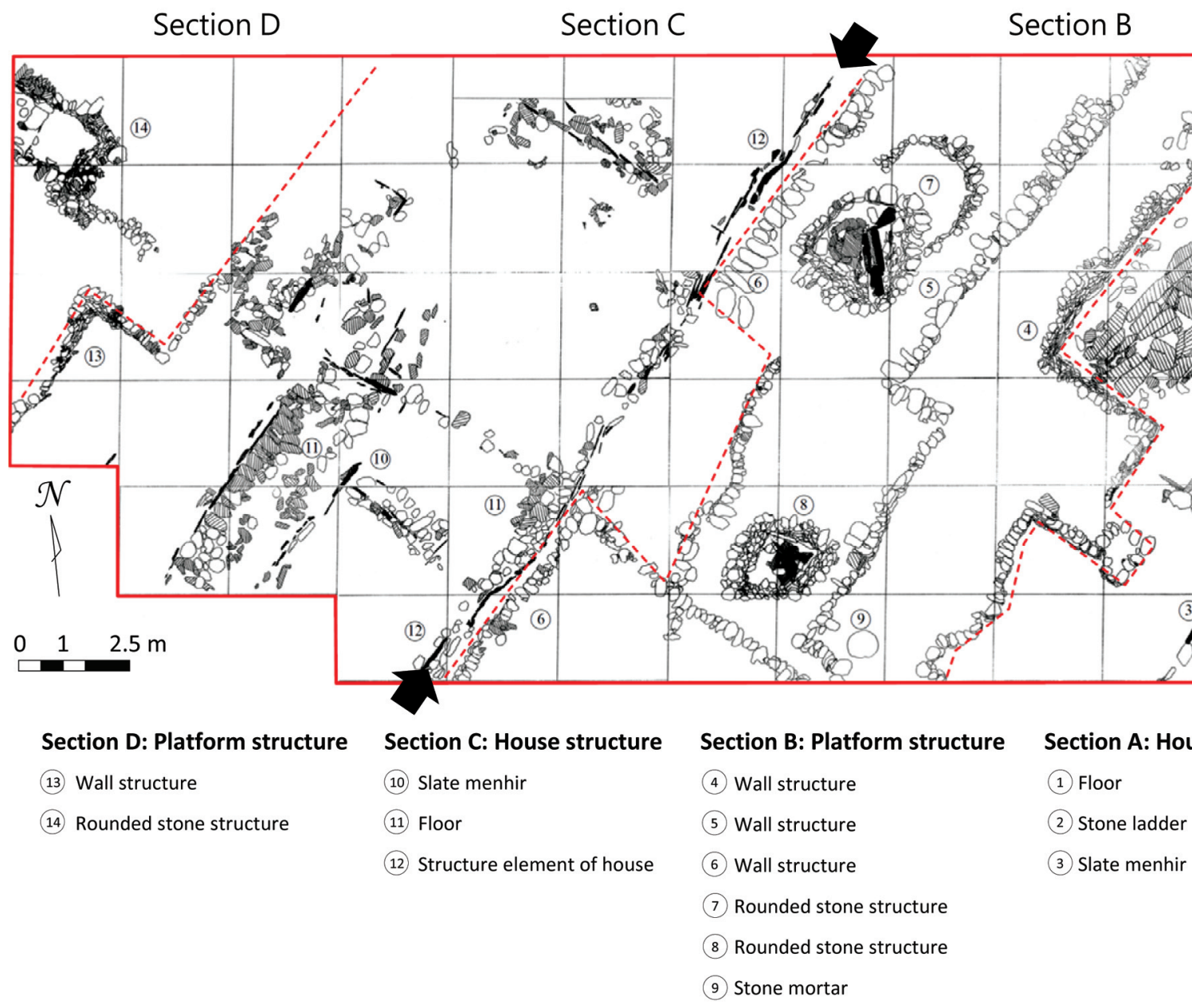

Fig. 5. The archaeological features observed at the onsite exhibition. The original drawing is provided by the National Museum of Prehistory. 

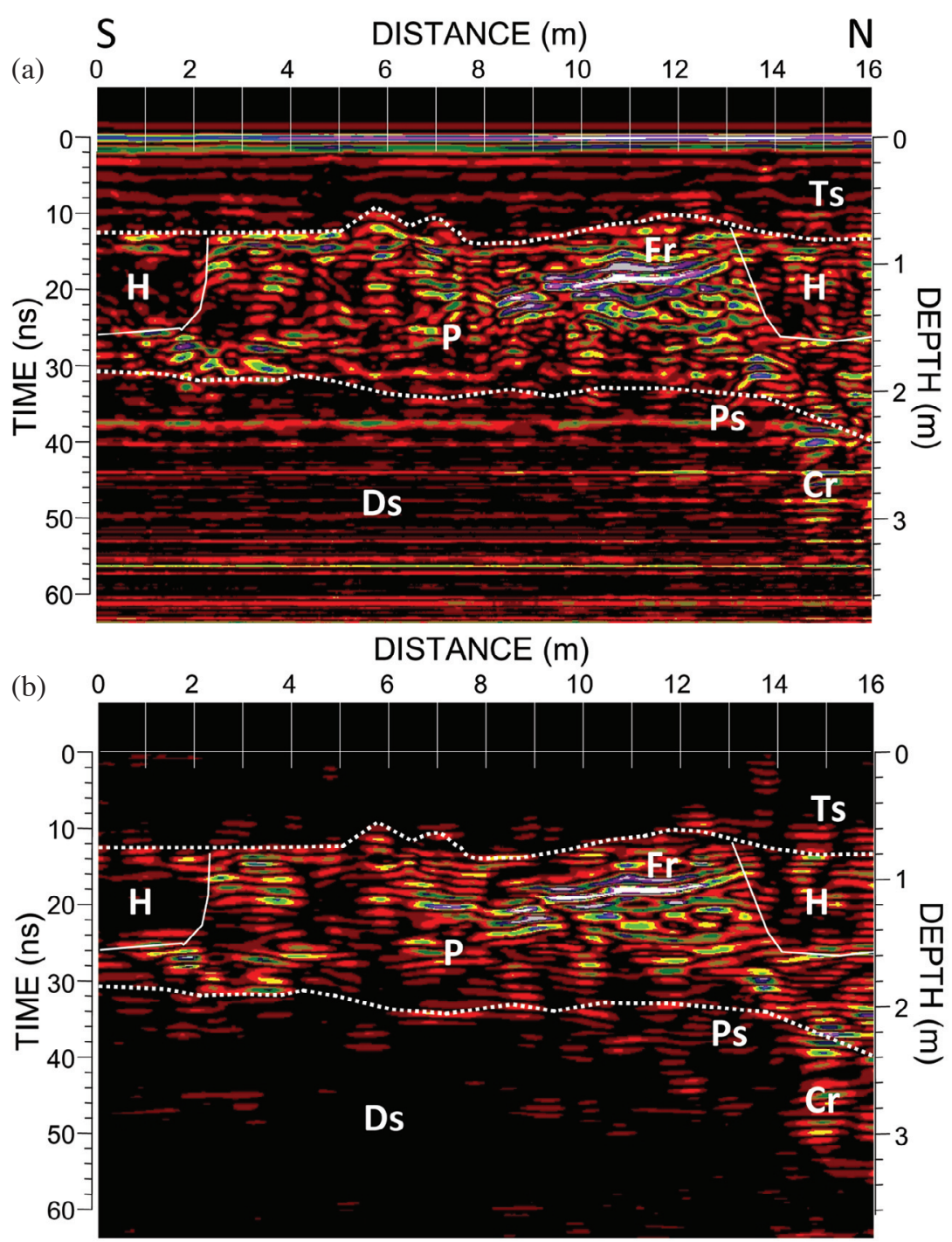

Fig. 6. The GPR image of profile B in sector 1. (a) Original GPR image. (b) Migrated GPR image.

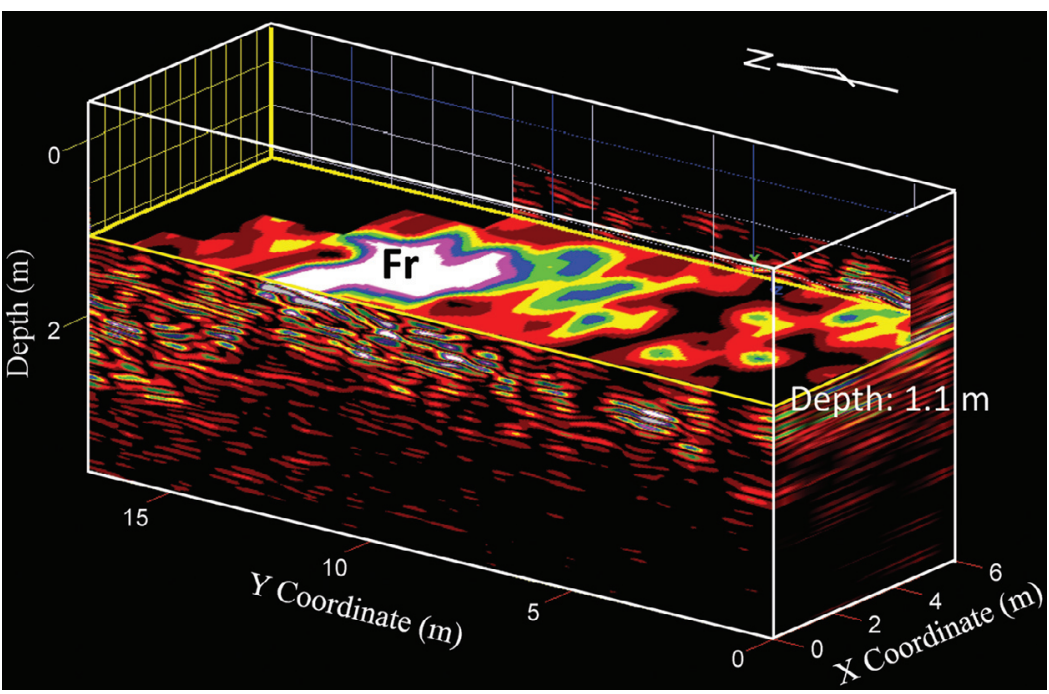

Fig. 7. The block view of the radar image in subsector 1a. The upper slice is cut at the depth of $1.1 \mathrm{~m}$. 


\section{PROSPECTING OF SECTOR 2}

Figure 5 shows the sketch of the archaeological feature observed at the onsite exhibition of the Peinan Cultural Park (Fig. 1). Archaeologists categorized it into 4 sections. Sections B and D denote the platform structure, which are composed mainly of boulders. Sections A and C denote the house structure filled with sediments, which consists of flat slate as the floor of the house. The area of the house structure contains rich archaeological articles, and is the most interesting area to pit for archaeological study.

The NMP planned to extent the current onsite exhibition for further demonstration of subsurface ancient remains. A detailed GPR survey was conducted at the northern extent of the onsite exhibition (Fig. 1). The purpose of this survey is to delineate the distribution of the subsurface buildings to help archaeologists precisely select the pit locations and to make a proper design of the new onsite exhibition. A $500 \mathrm{MHz}$ antenna was used for acquisition, and a set of NS parallel survey lines with $0.5 \mathrm{~m}$ spacing was performed to save time and obtain a high-resolution subsurface image. A total of 179 GPR images over an area of $3391 \mathrm{~m}^{2}$ were acquired.

The GPR-SLICE software was used for data processing. It consisted of horizontal filtering, band-pass filtering, automatic range gain, and Kirchhoff migration wherein the processing parameters used for this dataset are similar to those parameters used for the dataset acquired in sector 1 . The GPR signals within a specific thickness centered at a particular depth were gathered from all of the migrated GPR images to construct the depth slice after Kriging gridding. The depth slices are very helpful to display the subsurface structure at various depths (Goodman et al. 1995; Böniger and Tronicke 2010). Figure 8 shows 4 selected GPR depth slices of this survey area. Each GPR depth slice has a thickness of $5 \mathrm{~cm}$. The location of the onsite exhibition is also shown on the southern side of the survey area for comparison.

Based on the result obtained from sector 1, the highamplitude radar signals shown in Fig. 8a are related to the P-type signature, and the weak radar signals are related to the H-type signature. A comparison of Fig. 8a with Fig. 5 showed that the extensions of Sections B, C, and D well coincide with $\mathrm{P}_{3}, \mathrm{H}_{3}$, and $\mathrm{P}_{1}$, respectively. It shows that the scattered high-amplitude radar signals $\left(\mathrm{P}_{1}\right.$ to $\left.\mathrm{P}_{8}\right)$ may be related to the platform structure, and the area with low amplitude $\left(\mathrm{H}_{1}\right.$ to $\left.\mathrm{H}_{5}\right)$ between adjacent platform structures may be related to the house structure. The dashed white lines shown in Fig. 8 denote the boundary between the platform structure and house structure. As shown in Figs. 8b and c, obvious high radar signals in $\mathrm{H}_{1}$ and $\mathrm{H}_{2}$ were observed, which may be associated with the floors of the ancient house. The direction of the longitude of the house structure is approximately NE-SW, which is consistent with the findings from the previous excavation (Sung and Lien 2004; Lien and Sung 2006).

Furthermore, 2 notable anomalies, labeled $S_{1}$ and $S_{2}$, between the platform structure and house structure, as shown in Figs. 8b, c, and d, exhibited the characteristic of NE-SW extension and were parallel to each other. $S_{1}$ and $\mathrm{S}_{2}$ were clearer below a depth of $136 \mathrm{~cm}$ (Fig. 8b). This implies that $S_{1}$ and $S_{2}$ may relate to the deep-buried structure element of the house, which is denoted by the black arrow in Fig. 5.

Two test pits were undertaken to confirm the results from the GPR survey in sector 2. Their locations are shown in Figs. $8 \mathrm{a}$ and $\mathrm{b}$ as labeled $\mathrm{P}_{\mathrm{A}}$ and $\mathrm{P}_{\mathrm{B}}$, respectively. Figure 9 shows photographs taken at the test pits. The Pit $\mathrm{P}_{\mathrm{A}}$ (Fig. 9a) is located in the $\mathrm{H}_{3}$ (Fig. 8a). A portion of a manmade stone structure was found below the depth of $80 \mathrm{~cm}$. The Pit $\mathrm{P}_{\mathrm{B}}$ (Fig. 9b) is located on the boundary of $\mathrm{P}_{4}$. An obvious platform structure made of boulders was observed below the depth of about $10 \mathrm{~cm}$ on the western side of this pit and about $35 \mathrm{~cm}$ on the eastern side of this pit. The results observed from the pits are consistent with the GPR depth slices shown in Fig. 8.

\section{CONCLUSION}

The Peinan archaeological site is a crucial prehistoric archaeological site in Taiwan, and is protected by the Cultural Heritage Preservation Act. Only small-scale pits are allowed for archaeological research. Selecting the suitable pit locations using a geophysical survey is an essential task. A GPR survey was performed near the stone pillar to examine the GPR signatures of the subsurface archaeological targets at the Peinan site within the specific geology. A GPR survey with dense parallel survey lines was subsequently conducted at the candidate site of the new onsite exhibition for mapping the subsurface prehistoric house structures for future excavation plans.

The results of this study indicate that the GPR signatures at the Peinan site can be categorized into 7 types. Ts, Ps, and Ds denote topsoil, paleosurface, and deep stratum, respectively, which are the basic geological units/features in the Peinan site. The layer between Ps and the bottom of Ts is associated with the Peinan cultural layer. $\mathrm{P}$ and $\mathrm{H}$ denote the platform structure and house structure, respectively. $\mathrm{Cr}$ and Fr denote the slate coffin and large toppled slate, respectively.

A detailed image of the ancient building structures is reconstructed from the GPR survey with dense parallel survey lines in the northern area of the onsite exhibition. The results were verified by subsequent test pits, which indicate that the GPR depth-slices were successful in delineating the subsurface buildings. It will be quite helpful for future excavation plans and for making proper design of the new onsite exhibition. 

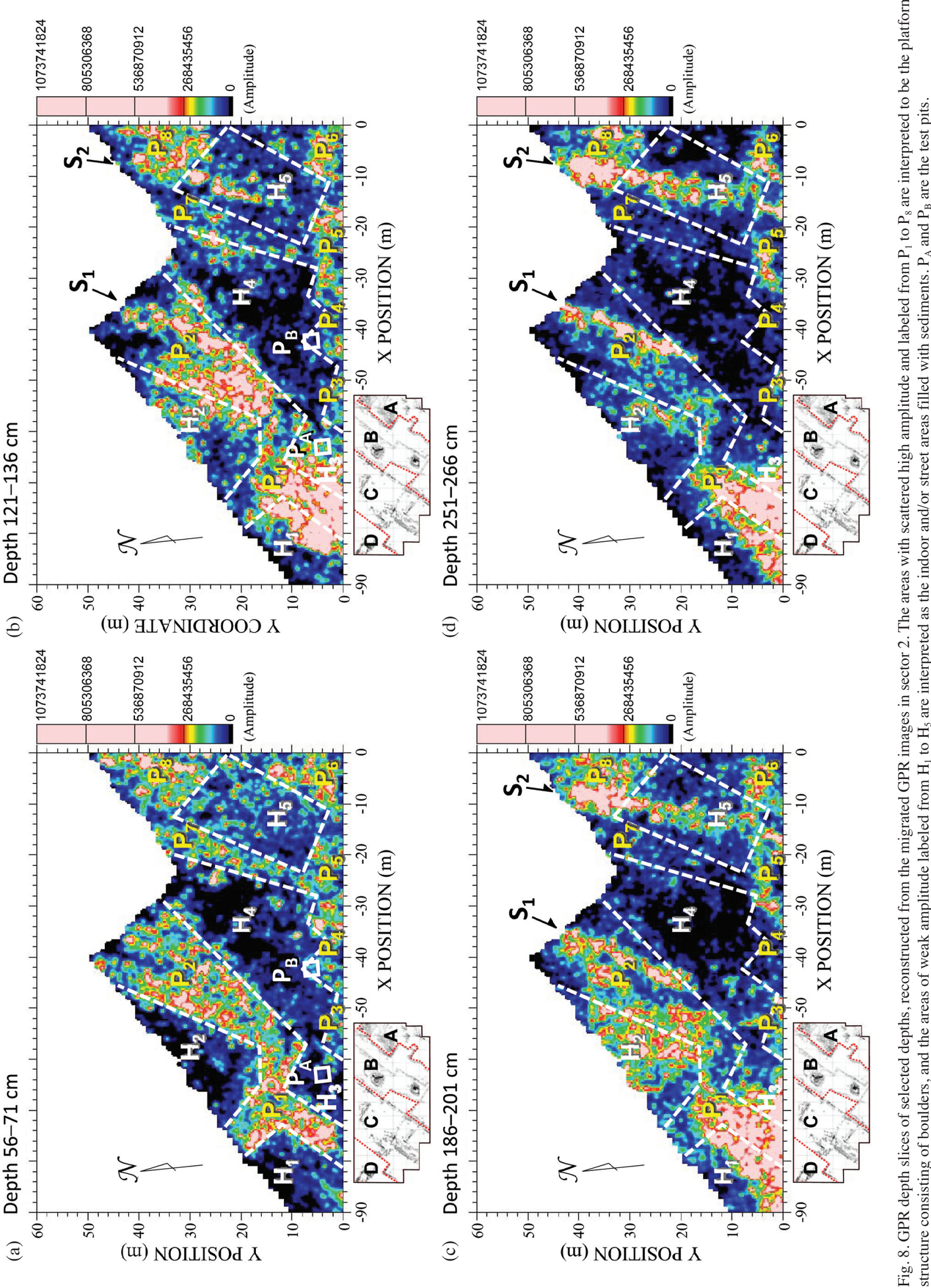
(a)

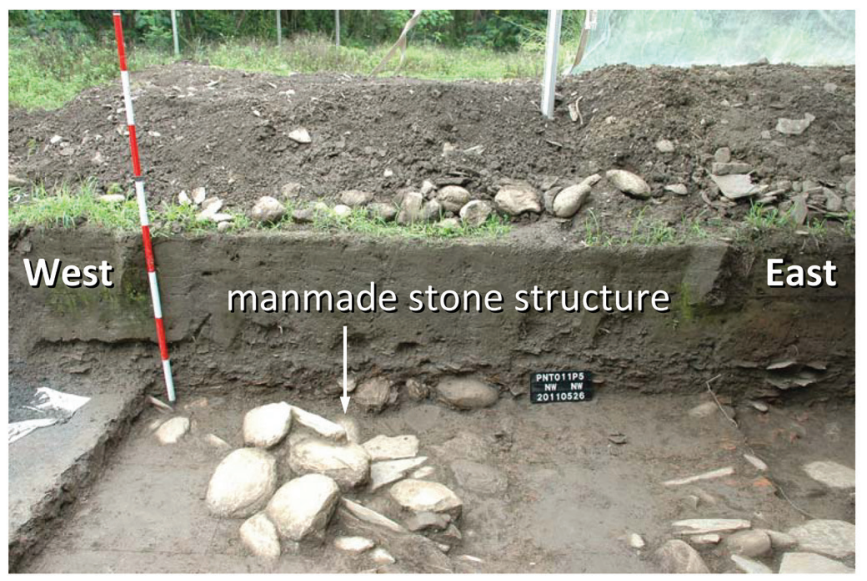

(b)

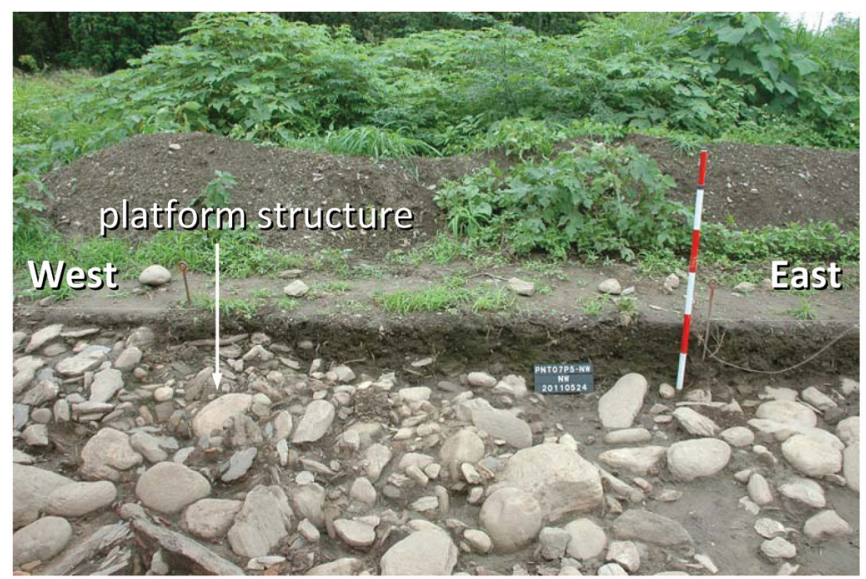

Fig. 9. Two photographs showing pit results according to the GPR results shown in Fig. 8. (a) Pit $P_{A}$. (b) Pit $P_{B}$.

Acknowledgements This work was financially supported by the National Museum of Prehistory, Taiwan. The author would like to thank Ms. Jin-Fong Cheng, Ms. Hsiang-Ling Kan, Mr. Chin-Chuan Tsai, Mr. Tong-Tsung Chung and Mr. Jung-Huei Chen for their assistance in field work. The authors would like to thank the reviewers for their constructive comments that helped to improve the text.

\section{REFERENCES}

Böniger, U. and J. Tronicke, 2010: Improving the interpretability of 3D GPR data using target-specific attributes: Application to tomb detection. J. Archaeol. Sci., 37, 360-367, doi: 10.1016/j.jas.2009.09.049. [Link]

Bonomo, N., L. Cedrina, A. Osella, and N. Ratto, 2009: GPR prospecting in a prehispanic village, NW Argentina. $J$. Appl. Geophys., 67, 80-87, doi: 10.1016/j.jappgeo.20 08.09.013. [Link]

Chen, C. S. and Y. Jeng, 2011: Nonlinear data processing method for the signal enhancement of GPR data. $J$. Appl. Geophys., 75, 113-123, doi: 10.1016/j.jappgeo. 2011.06.017. [Link]

Chen, H. W. and C. K. Ho, 1995: Application of GPR for archaeological investigation. Newsl. Chin. Ethnol., Acad. Sin., 33, 25-31. (in Chinese)

Francese, R. G., E. Finzi, and G. Morelli, 2009: 3-D highresolution multi-channel radar investigation of a Roman village in Northern Italy. J. Appl. Geophys., 67, 44-51, doi: 10.1016/j.jappgeo.2008.09.004. [Link]

Goodman, D., Y. Nishimura, and J. D. Rogers, 1995: GPR time slices in archaeological prospection. Archaeol. Prospect., 2, 85-89.

Ho, C. K., C. W. Cheng, and H. W. Chen, 1997: Excavation and GPR investigation of SuieWaKou archaeological site, Puli. TaiChung County Report. (in Chinese)
Hsiao, C. L. and L. T. Tong, 1995: Application of ground penetrating radar in the Peinan archaeological site. Newsl. Prep. office Natl. Mus. Prehi., 5, 1-24. (in Chinese)

Jeng, Y., Y. L. Lee, C. Y. Chen, and M. J. Lin, 2003: Integrated signal enhancements in magnetic investigation in archaeology. J. Appl. Geophys., 53, 31-48, doi: 10.1016/S0926-9851(03)00015-6. [Link]

Lee, K. S., 2009: The final report on archaeological investigation in the vicinity of Peinan Site. Taitung County Government Bureau of Cultural Affair, 71 pp. (in Chinese)

Leucci, G. and S. Negri, 2006: Use of ground penetrating radar to map subsurface archaeological features in an urban area.J. Archaeol.Sci., 33, 502-512, doi: 10.1016/ j.jas.2005.09.006. [Link]

Lien, C. M., 1991: The Neolithic archaeology of Taiwan and the Peinan excavations. Bull. Indo-Pac.Prehi. Assoc., 11, 339-352.

Lien, C. M., 2008: Studies on the Stratified Mortuary Data of Peinan in Neolithic Taiwan. National Taiwan University Press, 213 pp. (in Chinese)

Lien, C. M. and W. H. Sung, 2006: Peinan Excavations 1986 1989, Taiwan. National Taiwan University Press, 320 pp. (in Chinese)

National Museum of Prehistory (NMP), 2012: Peinan Cultural Park. Last accessed December 25, 2012, from http://en.nmp.gov.tw/index.php.

Porsani, J. L., G. M. Jangelme, and R. Kipnis, 2010: GPR survey at Lapa do Santo archaeological site, Lagoa Santa karstic region, Minas Gerais state, Brazil. J.Archaeol. Sci., 37, 1141-1148, doi: 10.1016/j.jas.2009.12.028. [Link]

Quarto, R., D. Schiavone, and I. Diaferia, 2007: Ground penetrating radar survey of a prehistoric site in southern 
Italy. J. Archaeol. Sci., 34, 2071-2080, doi: 10.1016/ j.jas.2007.02.024. [Link]

Shaaban, F. A., A. M. Abbas, M. A. Atya, and M. A. Hafez, 2009: Ground-penetrating radar exploration for ancient monuments at the Valley of Mummies - Kilo 6, Bahariya Oasis, Egypt. J. Appl. Geophys., 68, 194-202, doi: 10.1016/j.jappgeo.2008.11.009. [Link]

Sung, W. H., 1992: A note on the excavations at Peinan (Taiwan). BEFEO, 79, 281-286.

Sung, W. H. and C. M. Lien, 1987: An Archaeological Report on the $9^{\text {th }} \sim 10^{\text {th }}$ Terms of the Excavation at Peinan Site, Taiwan. National Taiwan University Press, Monograph 8. (in Chinese).

Sung, W. H. and C. M. Lien, 2004: Peinan excavations 1980 1982 - Analytical studies on the stratified sequence and the cultural remains from habitation levels. Taiwan National Taiwan University Press, 274 pp. (in Chinese)

Tong, L. T., 1993: Application of ground penetrating radar to locate underground pipes. Terr. Atmos. Ocean. Sci.,

\section{4, 171-178.}

Tong, L. T., 1995: Application of ground-penetrating radar in the Peinan archaeological site. Induustrial Technology Research Institute Report. (in Chinese)

Tong, L. T. and C. Y. Chen, 1996: Application of GPR to mapping shell mound in Kinmen. The Proceeding of $4^{\text {th }}$ Conference on the History of Science, 269-275. (in Chinese)

Tong, L. T., K. H. Lee, C. K. Yeh, Y. T. Hwang, and J. M. Chien, 2013: Geophysical study of the Peinan archaeological site, Taiwan. J. Appl. Geophys., 89, 1-10, doi: 10.1016/j.jappgeo.2012.11.004. [Link]

Travassos, J. M. and P. T. L. Menezes, 2004: GPR exploration for groundwater in a crystalline rock terrain. $J$. Appl. Geophys., 55, 239-248, doi: 10.1016/j.jappgeo. 2004.01.001. [Link]

Whiting, B. M., D.P.McFarland, and S. Hackenberger, 2001: Three-dimensional GPR study of a prehistoric site in Barbados, West Indies. J. Appl. Geophys., 47, 217-226, doi: 10.1016/S0926-9851(01)00066-0. [Link] 